\title{
Oxidation Behaviour of FeAl Intermetallics - The Formation of Pit-Like Holes on the Substrate
}

\author{
C-H. Xu, W. Gao * and H Gong \# \\ Department of Chemical \& Materials Engineering, \\ The University of Auckland, New Zealand. \\ *Corresponding Author, e-mail:w.gao@auckland.ac.nz \\ \# National University of Singapore
}

(Received January 7, 2000: final form March 27, 2000)

\begin{abstract}
Oxidation tests of FeAl intermetallics have been performed in ambient atmosphere at temperatures ranging from 1273 to $1473 \mathrm{~K}$. The morphologies of the oxidised specimens were studied using scanning electron microscopy (SEM) and atomic force microscopy (AFM). It was observed that pit-like holes with certain orientation formed on the surface of the FeAl substrates. The orientations of the pit walls were determined by tilt SEM experiments. The directions, volumes and formation mechanisms of the pit-like holes were discussed. These pit-like holes represent an important microstructural feature that is related to the adhesion ability of the oxide scales in $\mathrm{FeAl}$ intermetallic compounds.
\end{abstract}

Keywords: FeAl intermetallics, high temperature oxidation, oxide scale spallation, pits, tilt SEM experiment

\section{INTRODUCTION}

FeAl and $\mathrm{Fe}_{3} \mathrm{Al}$ intermetallics (containing 30-50 at. $\% \mathrm{Al}$ and $22.5-31.5$ at.\%Al, respectively) have advantages of relatively low density and cost, conservation of strategic metals, and good oxidation and sulphidation resistances. However, the scale spallation takes place during cyclic oxidation /1/. An important reason that causes scale spallation is the formation of pit-like holes (voids) on the oxide-substrate interface during oxidation $12 \%$. Holes formed on the alloy substrates usually have round or irregular shapes. It was reported that the pit-like holes also formed on a Ni-42Al alloy with certain orientation, but no explanation to the formation mechanism /3/. The formation of the holes relates to the scale growth mechanisms, representing an important microstructural feature that affects the adhesion ability of the oxide scales on many high temperature alloys.

The present work studies the morphologies of the pits-like holes formed on the substrate of $\mathrm{Fe}-37$ at.\%Al intermetallic compound during oxidation at 1273 1473K. The formation mechanisms of these pit-like holes were discussed based on the experimental results.

\section{EXPERIMENTS}

The test material was produced by melting Armco iron $(>99.9 \% \mathrm{Fe})$ and A58245 cast aluminium $(>99.9 \% \mathrm{Al})$ in a vacuum induction furnace followed by drop casting. The composition is 36.6 at.\%Al and balanced with $\mathrm{Fe}$. The cast ingot was annealed at $1373 \mathrm{~K}$ for 86,300 s for homogenisation. The size of FeAl grains is about $800 \mu \mathrm{m}$. Specimens were cut from the ingots with an ACUTOM diamond saw to the size of $2 \times 5 \times 1$ $\mathrm{mm}^{3}$, and ground successively with $\mathrm{SiC}$ papers and polished with $3 \mu \mathrm{m}$ diamond paste. The specimens were then degreased, rinsed and dried before oxidation tests. 
Thermogravimetric (TGA) measurements were used to study the oxidation kinetics. The oxidation experiment was performed in a Setaram TG-DSC 92 thermal analyser at temperatures ranging from 1273 to $1473 \mathrm{~K}$ in ambient atmosphere for $180,000 \mathrm{~s}$. The weight changes of the specimens were measured by an electronic balance with a weighting accuracy of $0.01 \mathrm{mg}$. The oxidised specimens were then cooled at a rate of $0.3 \mathrm{~K} / \mathrm{s}$ to room temperature.

After oxidation, the oxide scale on the surface spalled from the specimens during the cooling process. The oxidised specimens after scale spallation were coated with gold for SEM characterisation. The oxidised specimens were also observed using AFM. The orientation of pits was determined by tilt SEM experiment.

\section{RESULTS}

The mass-gain curves of FeAl were plotted in Figure 1 , showing that the oxidation reaction at 1273 to $1473 \mathrm{~K}$ obeyed an approximately parabolic rate law.

The oxide scales on the specimen surface spalled away during the cooling process. The morphologies of the oxide scales and the pit-like holes that were left on the substrates after scale spallation were influenced by the oxidation temperatures. The morphologies of a specimen oxidised at $1373 \mathrm{~K}$ are shown in Figure 2. Figure 2(a) is the bottom side of the spalled oxide scale, showing that the oxide grain size is non-uniform. The

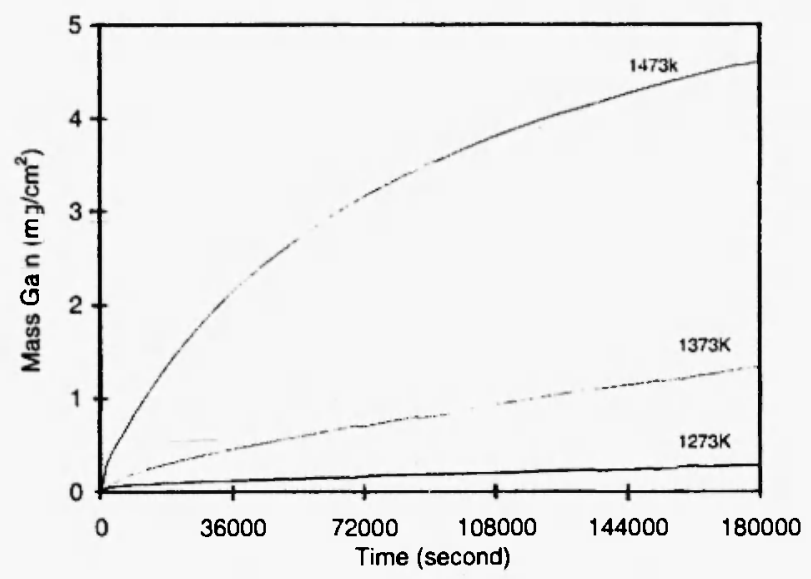

Fig. 1: Mass-gain vs. time for FeAl oxidation at 1273-1473K

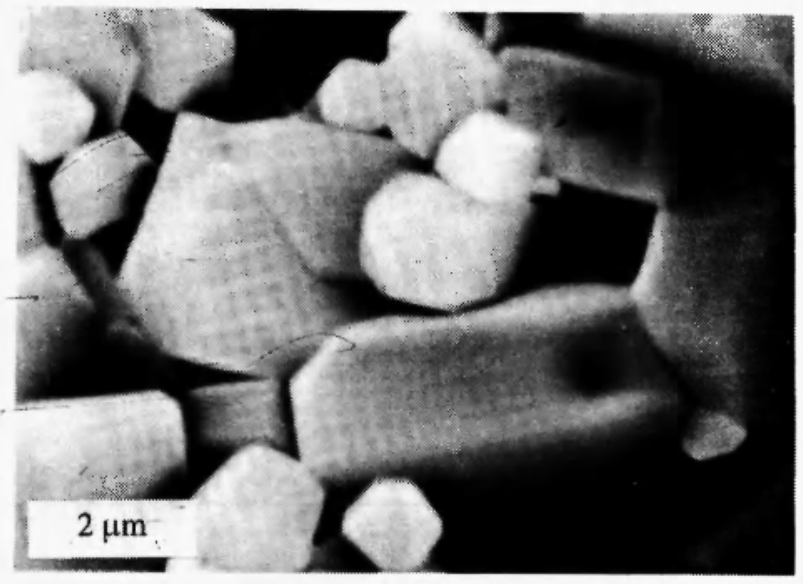

(a)

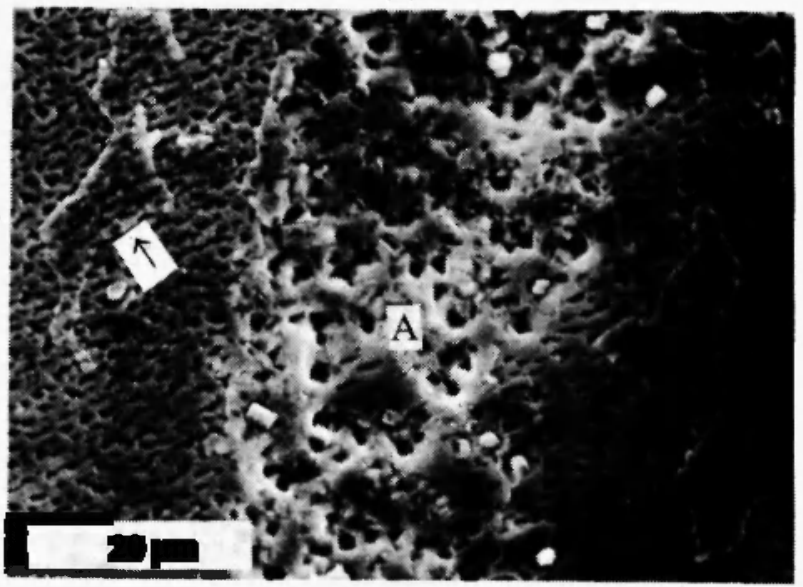

(b)

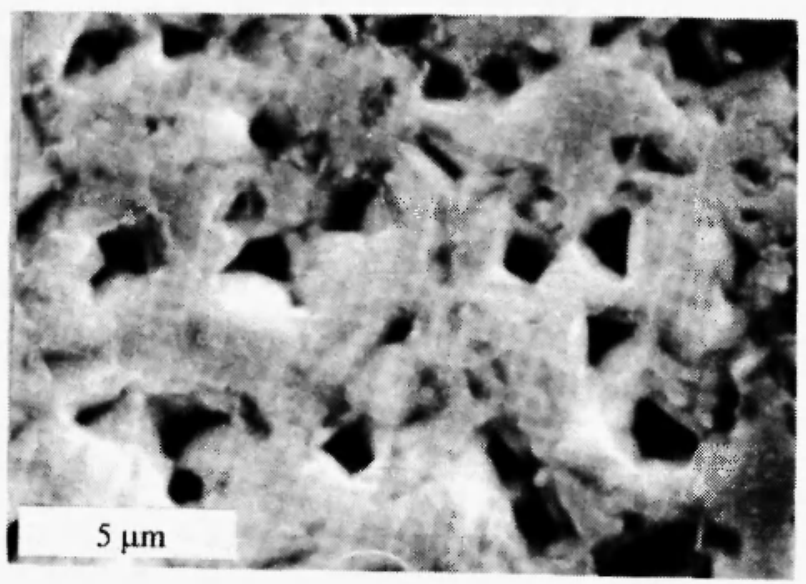

(c)

Fig. 2: The scales formed on Fe-37Al after oxidation at $1373 \mathrm{~K}$ for $180,000 \mathrm{~s}$ : (a) the bottom side of a spalled oxide, showing non-uniform oxide grains; (b) the substrate surface after scale spallation, showing small pits with certain orientations and some inner oxide layer on the substrate; (c) no inner oxide inside of the holes. 
typical morphology of the specimen surface after oxide scale spallation is shown in Figure 2(b). There are two kinds of feature for the holes formed on the substrate: the pits with special orientations and the holes with random orientations (marked A). There is a partially broken thin oxide layer (pointed by an arrow in Figure 2(b)) under the outside oxide layer. The feature on area $A$ in Figure 2(b) matches that on the bottom side of the spalled scale shown in Figure 2(a), indicating that the substrate on area $\mathrm{A}$ was connected to the outside oxide scale at high temperature. However, no thin inner oxide layer can be seen inside the holes on area $A$ shown in Figure 2(c). The specimens oxidised at $1473 \mathrm{~K}$ showed similar morphologies to those oxidised at $1373 \mathrm{~K}$, although the inner oxide layer was thicker than that of oxidised at $1373 \mathrm{~K}$.

After oxidation at $1273 \mathrm{~K}$, most oxide scales spalled away although some broken oxide pieces can still be seen on the surface of the specimen (Figure 3). There

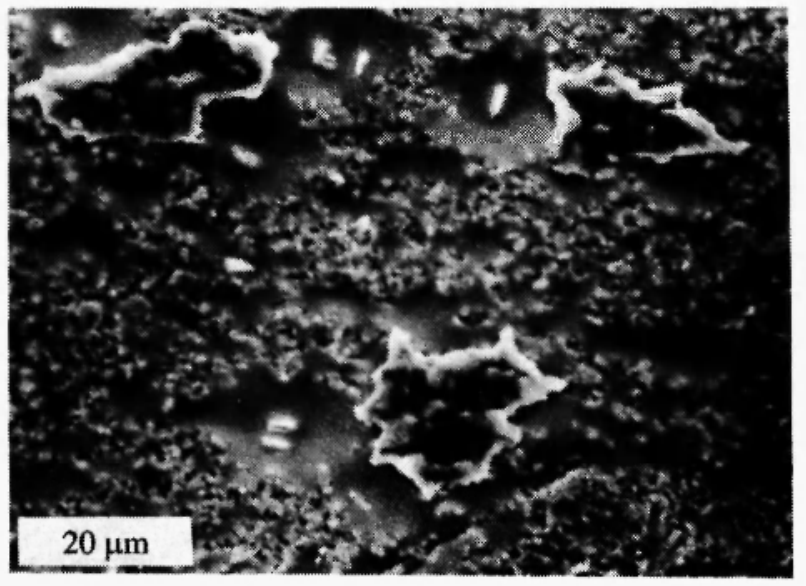

Fig. 3: Oxide scales formed on $\mathrm{Fe}-37 \mathrm{Al}$ after oxidation at $1273 \mathrm{~K}$ for 180,000 s.

are some flat areas and some un-even areas on the substrate after scale spallation. It is believed that voids were formed on the flat areas at high temperature. Therefore, these areas are flat after the scale breaking away. These areas do not show clear pit-shape under SEM, but shallow pits with certain orientation could be seen in AFM image in Figure 4. Oxide was connected to the substrate at the un-even areas during high temperature oxidation.

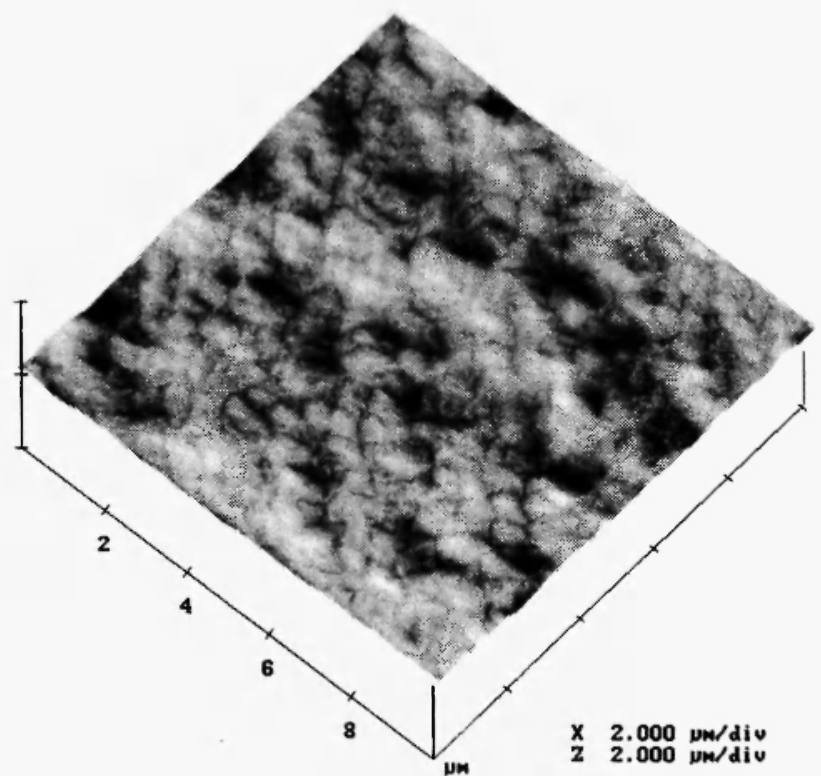

Fig. 4: AFM images from the surface of $\mathrm{Fe}-37 \mathrm{Al}$ after oxidation at $1273 \mathrm{~K}$ for 180,000 s, showing shallow pits on the substrate.

Figure 5 shows AFM images of the substrate surface after oxidation at $1373 \mathrm{~K}$ for $180,000 \mathrm{~s}$. Pit holes were distributed uniformly on the surface. A thin layer of oxide could be seen after the outside scale breaking away, as shown at the bottom part of Figure 5(a). AFM image analysis in Figure 5(a) indicated that the thickness of the thin oxide layer was $-100 \mathrm{~nm}$. No oxide could be found inside of the pit holes. Figure 5(b) is an AFM image of a pit with a cross section profile, showing that the average depth of the pits was $\sim 55 \mathrm{~nm}$, with which the volume of the pits was calculated.

The shape of the pit holes seems dependent on the FeAl grain orientations. In order to determine the orientation of the pit walls, several pyramid-shape pits with 4-fold symmetry were observed under SEM. When the specimen was continuously tilted to a certain degree, the adjacent pit walls became an angled line as shown in Figure $6(\mathrm{c})$. The tilting process is shown in Figure 6 with the tilt-angle of $0,20^{\circ}$ and $45^{\circ}$. The angle between the adjacent pit walls was measured to be $\sim 120^{\circ}$ in Figure 6(c). 


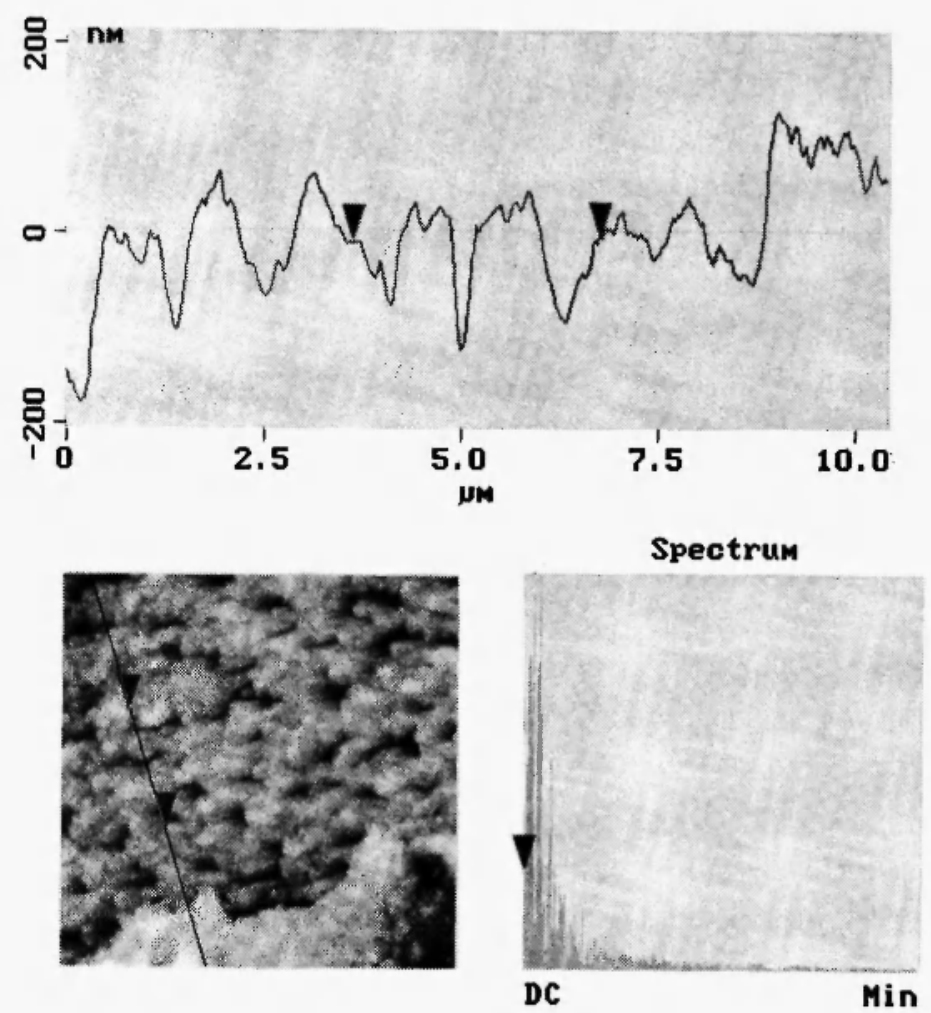

(a)
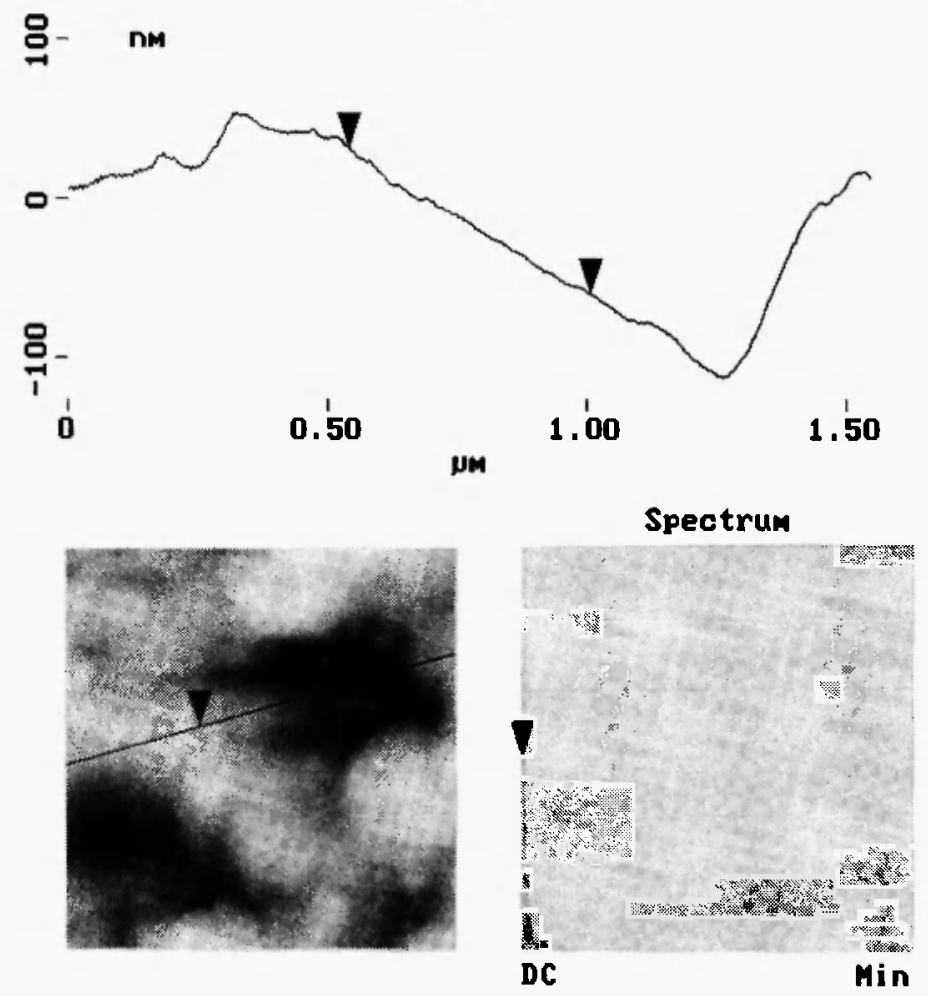

(b)

Fig. 5: (a) AFM innages of a substrate surface after oxidation at $1373 \mathrm{~K}$ in air for 180,000 s, showing the thickness of inner oxide layer and (b) a typical pit with the cross section profile 


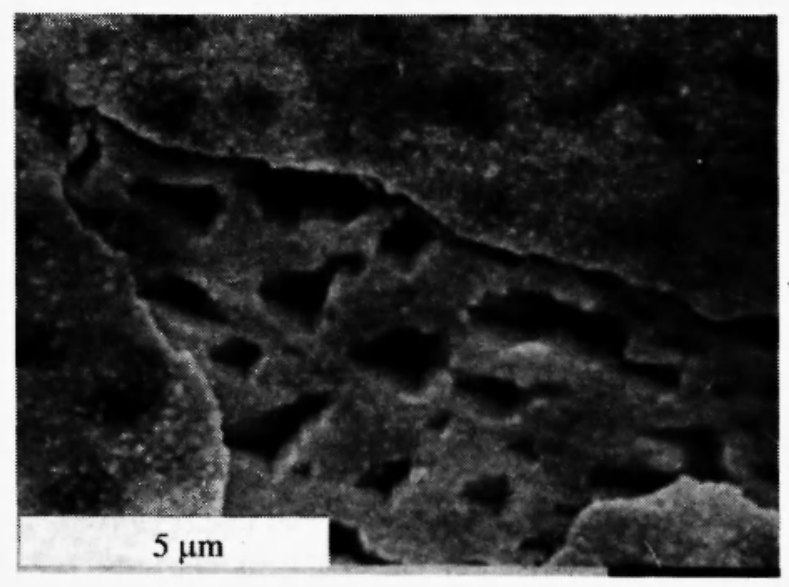

(a)

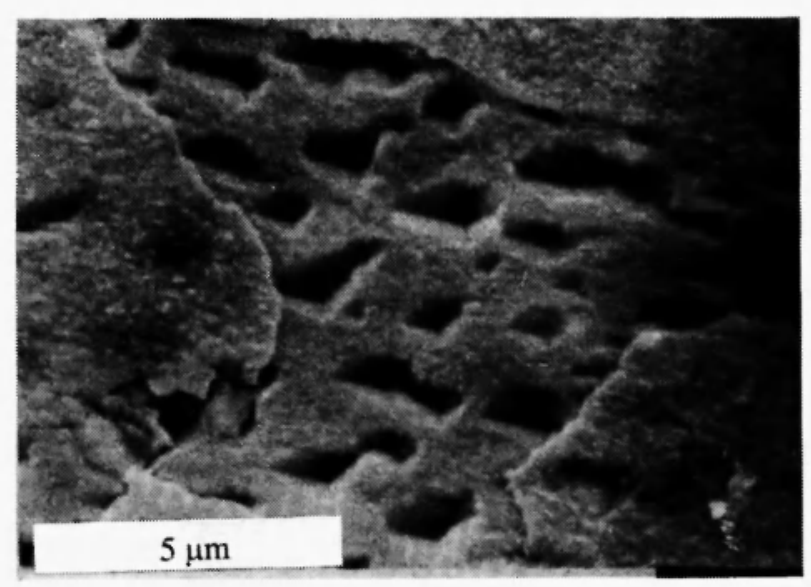

(b)

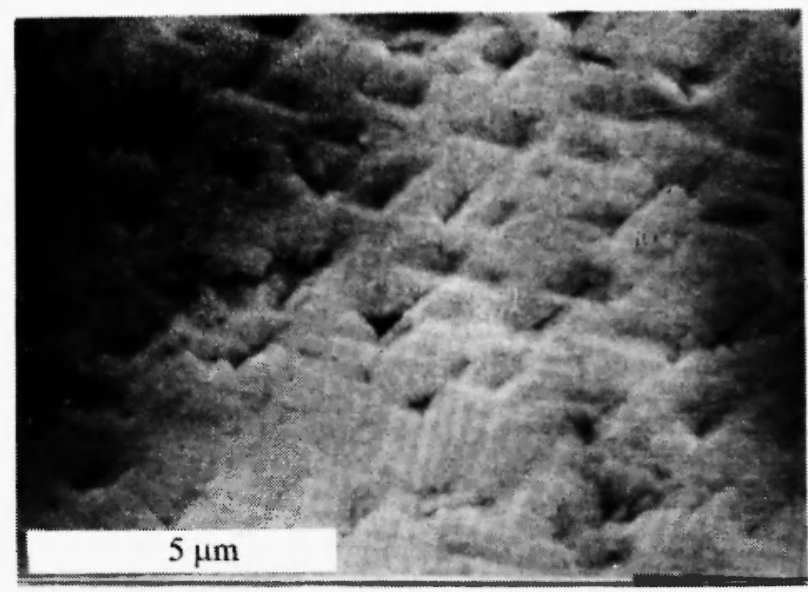

(c)

Fig. 6: Tilt SEM micrographs showing the orientation of the pit walls. Tilt to an angle of (a) $0^{\circ}$, (b) $20^{\circ}$ and (c) $45^{\circ}$

\section{DISCUSSIONS}

\subsection{Mass Balance of the Oxides and Pits}

The volumes of the oxides and the pits can be evaluated to analyse the mechanism of scale growth. The volume of pits formed during oxidation was estimated by measuring their dimensions. AFM images such as Figure $5(\mathrm{~b})$ was used to make this measurement. The average volume of a pit hole was measured as $55 \times 710 \times 710 \mathrm{~nm}^{3}$. The density of pits was $-70 / 100 \mu \mathrm{m}^{2}$. Then the volume of the pits per unit area can be calculated as $2.0 \times 10^{-6} \mathrm{~cm}^{3} / \mathrm{cm}^{2}$.

The volume of the oxide formed during oxidation can be calculated with the measured mass gain. The mass gain of $\mathrm{FeAl}$ at $1373 \mathrm{~K}$ for $180,000 \mathrm{~s}$ is 1.33 $\mathrm{mg} / \mathrm{cm}^{2}$. Based on the following chemical reaction:

$$
2 \mathrm{Al}+(3 / 2) \mathrm{O}_{2}=\mathrm{Al}_{2} \mathrm{O}_{3}
$$

The weight of $\mathrm{Al}_{2} \mathrm{O}_{3}(W)$ formed after oxidation for $180,000 \mathrm{~s}$ was calculated as $2.82 \mathrm{mg} / \mathrm{cm}^{2}$. The density of the $\mathrm{Al}_{2} \mathrm{O}_{3}$ oxide $\rho=3.96 \mathrm{~g} / \mathrm{cm}^{3} / 4 /$. According to the relation of $\rho=W / V$, the thickness of the oxide scale $\delta$ can be calculated as $\sim 7.1 \mu \mathrm{m}$. The thickness of the thin inner oxide layer on the substrate is estimated as $\sim 0.1$ $\mu \mathrm{n}$ by AFM analysis (Figure 5(a)). Therefore, the majority of the oxide scale $(\sim 7 \mu \mathrm{m})$ was spalled away during oxidation.

The volumes of the consumed $\mathrm{Al}$ can also be calculated with the concept of P-B ratio for alloys, which can be expressed as $P B R=$ (Volume of Oxide)/(Volume of Assumed Metal in Alloy) 15/. The $\mathrm{P}-\mathrm{B}$ ratio of $\mathrm{FeAl}$ alloy was then calculated as $\sim 1.7$. To form $7 \mu \mathrm{m} \mathrm{Al}_{2} \mathrm{O}_{3}$, the calculated volume of the consumed $\mathrm{Al}$ is $\sim 4 \times 10^{-4} \mathrm{~cm}^{3} / \mathrm{cm}^{2}$, much greater than the volume of the pit holes $\left(2.0 \times 10^{-6} \mathrm{~cm}^{3} / \mathrm{cm}^{2}\right)$. However, the volume of $\mathrm{Al}$ that is required to form $0.1 \mu \mathrm{m}$ inner $\mathrm{Al}_{2} \mathrm{O}_{3}$ layer is $5.7 \times 10^{-6} \mathrm{~cm}^{3} / \mathrm{cm}^{2}$, close to the volume of the pit holes.

It is known that an oxidation process is controlled by either cation or anion diffusion or both. When the cation diffusion dominates the process, voids are produced in the substrate near the interface. It has been reported that both $\mathrm{Al}$ and $\mathrm{O}$ ion diffusion take place in the oxidation processes of $\beta$-NiAl and $\mathrm{FeCrAl}$ alloys $/ 6 /$. In the present case, the volume of $\mathrm{Al}$ that is required to form 
$0.1 \mu \mathrm{m}$ inner $\mathrm{Al}_{2} \mathrm{O}_{3}$ is close to the volume of the pit holes, implying that the inner oxide layer is probably formed by Al outwards diffusion. The outside oxide layer is perhaps formed by both oxygen and $\mathrm{Al}$ diffusions.

\subsection{Mechanism of Pit Formation}

The formation of the pits is believed due to the evaporation of Al. From Figures 2(a) and 2(b), it can be seen that the structure feature in the pit areas did not match the spalled scale, implying that the pits formed after the scale was detached from the alloy during oxidation at the high temperature. Therefore, Al had to across the gap between the alloy and scale to supply oxide growth. The evaporation rate of $\mathrm{Al}$ at the structure defects should be higher than in the normal crystal lattice areas. All types of structural defects including linear, planar and volume defects promoted the evaporation of $\mathrm{Al}$ and consumed more $\mathrm{Al}$ than in the crystal lattice areas. From Figure 2(b), it can be seen that the distribution of pits was quite uniform, suggesting that the pits initiated at randomly distributed defects like dislocations. Since $\mathrm{Al}$ evaporated faster at the defect positions than the lattice areas $\left(V_{D}>V_{L}\right)$, pits formed on the surface. Also the diffusion rates along and across the dislocation lines may be different $\left(V_{D} \neq V_{C}\right)$, which decide the shape of the pits. Therefore, the depth and shape of the pits are determined by the ratios of $V_{D} / V_{L}$ and $V_{D} / V_{C}$, as shown in Figure 7 . This situation is similar to chemical etching, in which the formation of pits is affected by a number of external and internal factors including temperature, time and crystal structure. In this experiment, the pits were very small on the

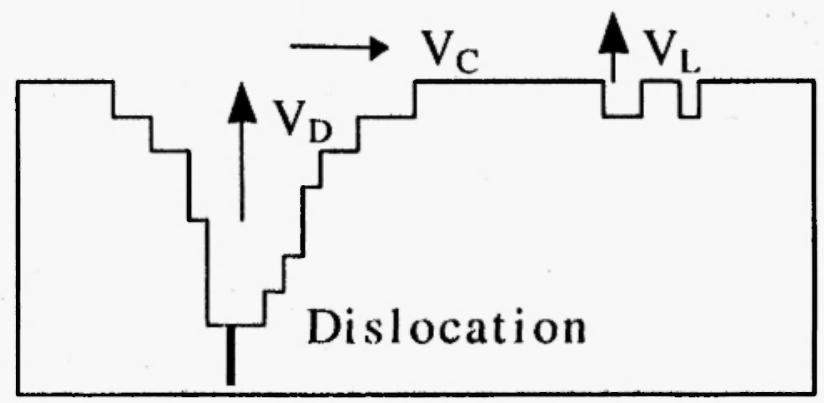

Fig. 7: Illustration of pit formation due to different evaporation rates of $\mathrm{Al}$ specimens oxidised at $1273 \mathrm{~K}$ (Figure 4), probably because $V_{D} / V_{C}$ was not large enough to form deep pits.

\subsection{Determination of the Pit Orientation}

Tilt SEM experiment was used before to determine the crystal orientations of pits 171 . The shape of the pit holes also depends on the grain orientations. The pits on FeAl in Figure 6(a) showed an opposite pyramid shape with 4-fold symmetry. After tilting, the adjacent pit walls were appeared as a $120^{\circ}$ angled line (Figure 6(c)), which is characteristic of the $\{111\}$ plane for the cubic lattice in Figure 8. When the $\{111\}$ plane is parallel to

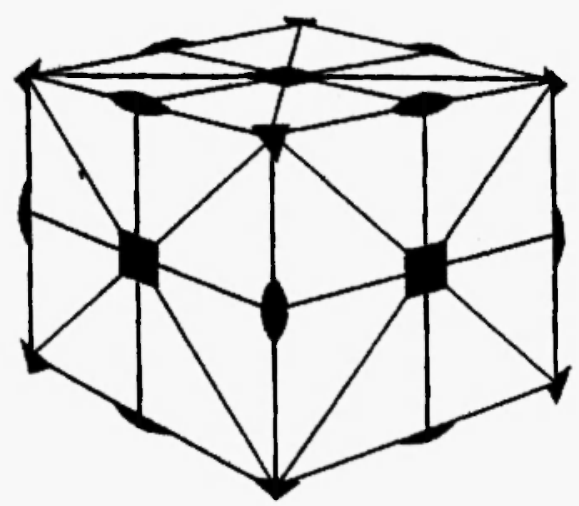

Fig. 8: Symmetry elements in a cube: $\nabla$-fold symmetry

the paper surface, a 3 -fold symmetry axis, $\langle 111\rangle$, is perpendicular to the paper surface. Therefore, the pit walls are nominally $\{110\}$ planes determined by the crystal symmetry, as shown in Figure 9.

Pits always possess an external shape, which may be polygonal or round. As discussed above, the geometry of the pits is determined by the relative rates of atom removal along the different crystal orientations. To analyse this, the bonding energies of atoms along different crystal orientations should be considered. In a bcc crystal structure, the most densely packed and lowest index planes such as $\{100\},\{110\}$ and $\{111\}$ are likely to be attacked first. Figure 10 shows the crystal structure of FeAl: Al is located in the centre of the cubic cell and $\mathrm{Fe}$ at the corners. The most densely packed direction in bcc is $\langle 111\rangle$, which contains Fe-Al bonds. The densities of the Fe-Al bonds along $\{100\},\{111\}$ 


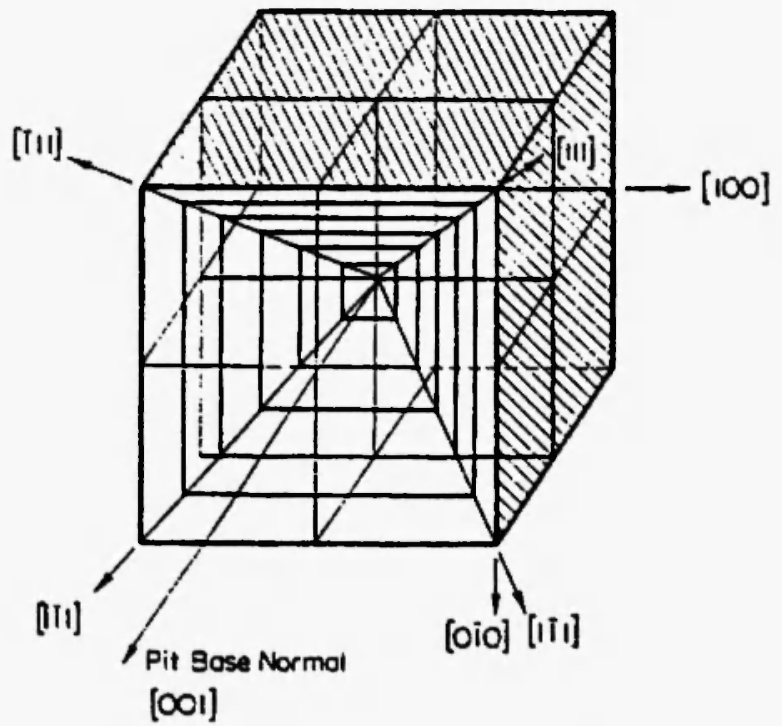

Fig. 9: Schematic drawing of a pit in the front face of a cube

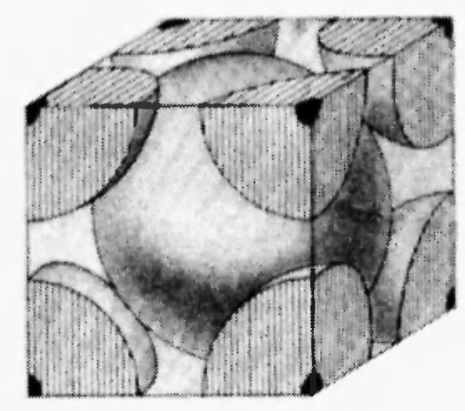

Fig. 10: The lattice structure of $\mathrm{FeAl}$ : an $\mathrm{Al}$ atom is in the centre of the cubic cell and $\mathrm{Fe}$ atoms are at the corners

and (110) planes can be calculated as 4, 3.5 and 2.8 for a unit area of $a^{2}$, respectively. Therefore, the bonds on $\{110\}$ planes are the weakest and easy to be broken. This explains why the pit walls are most likely to be $\{110\}$ planes, and the shape of the pits shows an opposite pyramid shape with 4-fold symmetry from $<100>$ direction view.

\section{CONCLUSIONS}

1. The oxide scales formed on $\mathrm{FeAl}$ after oxidation at $1273-1473 \mathrm{~K}$ for 180,000 s include an outside oxide scale and an inner oxide layer. The outside oxide scale totally spalled and the inner oxide layer partially spalled during the cooling stages. The growth of the outside oxide scales is believed to be controlled by both $\mathrm{Al}$ outward-diffusion and $\mathrm{O}$ inward-diffusion, while the inner oxide scale growth is controlled by $\mathrm{Al}$ outward-diffusion.

2. Pit-like holes formed on the FeAl substrate after oxidation at 1373 and $1473 \mathrm{~K}$ for 180,000 s. The pits show an opposite pyramid shape with 4-fold symmetry from $\langle 100\rangle$ direction, and the pit walls are likely to be on the $\{110\}$ planes. The volume of the pit holes is $\sim 2.0 \times 10^{-6} \mathrm{~cm}^{3} / \mathrm{cm}^{2}$. The pits formed during oxidation at $1273 \mathrm{~K}$ are shallow and could not be identified by SEM.

3. The formation mechanism of the pits is analysed based on the scale morphology. It is believed that the evaporation of $\mathrm{Al}$ across the gap between the substrate and scale left the pit holes on the substrate. Pits are formed when the diffusion rate along the dislocation lines is significantly greater than the diffusion rate across the lines $\left(V_{D}>V_{L}\right)$. The shape of the pits is also determined by the ratio of $V_{D} / V_{C}$.

\section{ACKNOWLEDGEMENTS}

The authors would like to thank the Department of Chemical \& Materials Engineering, and Research Centre for Surface and Materials Research for various experimental support.

\section{REFERENCES}

1. J.H. Devan, Oxidation of High Temperature Intermetallics, T. Grobstein (ed.). Warrendale, PA, TMS, 1989, pl07.

2. C-H. Xu and W. Gao, "Structure and Spallation of Oxide Scale of Oxidised Fe-22Al Intermetallics". Proceedings of the Third New Zealand Postgraduate Conference for Engineering and Technology Students, 1-2 July, 1996, p275.

3. J.L. Smialek, Metallurgical Transactions A,. 9A, 309, 1978). 
4. J.F. Shackelford, CRC Materials Science \& Engineering Handbook, International Standard Book, No 0849342503, 1994, p51.

5. $\mathrm{C}-\mathrm{H} \mathrm{Xu}$ and $\mathrm{W}$. Gao, Materials Research Innovation, 3 (4), 1-10 (1999).

6. B.A. Pint, J.R. Martin, and L.W. Hobbs, Oxidation of Metals, 39 (3/4), 167-194 (1995).

7. L.E. Matson, H. Erhart, M. Lee and R.A. Rapp, Metallurgical Transactions A, 15A, 2241 (1984). 